\title{
Presença de pets e sua relação com seus tutores
}

\author{
Presence of pets and their relationship with their tutors \\ Presencia de mascotas y su relación con sus tutores
}

Recebido: 09/04/2021 | Revisado: 20/04/2021 | Aceito: 26/04/2021 | Publicado: 10/05/2021

Tamires Silva dos Santos

ORCID: https://orcid.org/0000-0002-5440-7274 Universidade Federal de Pelotas, Brasil E-mail: myres_santos@hotmail.com

Clederson Idenio Schmitt

ORCID: https://orcid.org/0000-0001-7948-9627 Universidade Federal de Pelotas, Brasil Instituto Federal de Educação, Ciência e Tecnologia Sul-Riograndense, Brasil E-mail: schmittproducoes@gmail.com

Tatila Lobo Ochôa

ORCID: https://orcid.org/0000-0003-3103-1494 Universidade Federal de Pelotas, Brasil E-mail: medvetalitaochoa@gmail.com

Fernanda Rodrigues Mendonça

ORCID: https://orcid.org/0000-0002-6395-4448 Universidade Federal de Pelotas, Brasil

E-mail: nandarm.vet@gmail.com

\begin{abstract}
Resumo
O relacionamento humano com animais domésticos é muito antigo, e as pessoas precisam dos animais em suas vidas. Existe uma relação dinâmica e mutuamente benéfica entre pessoas e outros animais, influenciada pelos comportamentos essenciais para a saúde e bem estar de ambos. Com essa crescente relação do animal com o ser humano, é importante realizar levantamento populacional nas cidades. Diante do contexto, o trabalho teve como objetivo avaliar ocorrência de caninos e felinos domiciliados no município de Pelotas, buscando relacionar os fatores que levaram a escolha de ter um pet em casa. Para isso, elaborou-se um questionário on-line pelo Google Forms, com objetivo de identificar a ocorrência de cães e ou gatos no munícipio de Pelotas - RS. A presença de animais de estimação em casa, está presente nos lares de $236(86,4 \%)$ das pessoas que responderam. Podemos observar que a presença de gatos nos lares da cidade de Pelotas - RS chega a $28 \%$ quando analisamos as respostas das pessoas possui um gato pelo menos, mostrando a tendência do aumento do número de gatos em relação ao número de cães. A adoção dos pets foi dada com a preferência pelos tutores, como forma de ter um pet em casa. Além disso, há a tendência de que os pets estão ocupando um lugar dentro da família, já que muitos moram sozinho e ele torna-se um amigo e até mesmo um filho.
\end{abstract}

Palavras-chave: Animais de estimação; Cão; Gato.

\begin{abstract}
The human relationship with domestic animals is very old, and people need the animals in their lives. There is a dynamic and mutually beneficial relationship between people and other animals, influenced by the behaviors essential to the health and well-being of both. With this growing relationship between the animal and the human being, it is important to conduct a population survey in the cities. In view of the context, the study aimed to evaluate the occurrence of canines and felines domiciled in the municipality of Pelotas, seeking to relate the factors that led to the choice of having a pet at home. For this, an online questionnaire was elaborated by Google Forms, in order to identify the occurrence of dogs and or cats in the municipality of Pelotas - RS. The presence of pets at home is present in the homes of $236(86.4 \%)$ of the people who responded. we can observe that the presence of cats in the homes of the city of Pelotas - RS reaches $28 \%$ when we analyze the responses of people has a cat at least, showing the tendency of increasing the number of cats in relation to the number of dogs. The adoption of pets was given with the preference for tutors, as a way to have a pet at home. In addition, there is a tendency that pets are occupying a place within the family, since many live alone and he becomes a friend and even a son.
\end{abstract}

Keywords: Pets; Cat; Dog.

\section{Resumen}

La relación humana con los animales domésticos es muy antigua, y la gente necesita a los animales en sus vidas. Existe una relación dinámica y mutuamente beneficiosa entre las personas y otros animales, influenciada por los comportamientos esenciales para la salud y el bienestar de ambos. Con esta creciente relación entre el animal y el ser humano, es importante realizar una encuesta de población en las ciudades. En vista del contexto, el estudio tuvo como objetivo evaluar la ocurrencia de caninos y felinos domiciliados en el municipio de Pelotas, buscando relacionar los 
factores que llevaron a la elección de tener una mascota en casa. Para ello, Google Forms elaboró un cuestionario en línea, con el fin de identificar la aparición de perros y gatos en el municipio de Pelotas - RS. La presencia de mascotas en casa está presente en los hogares de $236(86,4 \%)$ de las personas que respondieron. podemos observar que la presencia de gatos en los hogares de la ciudad de Pelotas - RS alcanza el 28\% cuando analizamos las respuestas de las personas tiene un gato al menos, mostrando la tendencia a aumentar el número de gatos en relación con el número de perros. La adopción de mascotas se dio con la preferencia por los tutores, como una manera de tener una mascota en casa. Además, existe una tendencia a que las mascotas estén ocupando un lugar dentro de la familia, ya que muchos viven solos y se convierte en un amigo e incluso un hijo.

Palabras clave: Mascota; Gato; Perro.

\section{Introdução}

O relacionamento humano com animais domésticos é muito antigo, e as pessoas precisam dos animais em suas vidas, pesquisa mais recente com DNA dos cães provou que seres humanos e cachorros podem estar convivendo há mais de cem mil anos (Heisen 2009). Isso ocorreu porque nos primórdios de 10mil a.C já ocorria a interação entre homens e canino (Rodrigues et al., 2012). O que corrobora com circunstâncias que apontam ser a espécie canina a primeira a sofrer domesticação há aproximadamente 12.000 anos, (Magnabosco, 2006). Já os felinos domésticos, por sua vez, têm seu surgimento datado há mais de 100 mil anos, tendo como possível origem o cruzamento de cinco espécies selvagens, e sua domesticação ocorreu há cerca de 10 a 12 mil anos (Montague et al.; 2014). Concomitantemente ao surgimento dos primeiros cultivos de cereais, que atraiam roedores, os agricultores começaram a observar que os gatos eram sublimes caçadores, o que proporcionou a aproximação dos humanos aos gato (Montague et al.; 2014, Oliveto, 2011).

Devido a semelhança entre a estrutura social dos humanos e das matilhas pode ter ocorrido o vínculo entre o cão e o homem, e com o passar do tempo os laços afetivos acabaram por fortalecer ainda mais essa relação (Rodrigues et al., 2012). Simultaneamente, os cães começaram a exercer diversas atividades tais como vigilância, transporte de arados e trenós e pastoreio de animais (Magnabosco, 2006). E essa relação, foi sofrendo alterações, aproximando cada vez mais o pet das relações humanas, culminando com a sua progressiva e atual inclusão no âmbito familiar (Delarissa, 2003).

Conforme a Associação Americana de Medicina Veterinária, existe uma relação dinâmica e mutuamente benéfica entre pessoas e outros animais, influenciada pelos comportamentos essenciais para a saúde e bem estar de ambos (Faraco, 2008). Com isso é possível observar que a cada ano cresce o número de cães e gatos nos lares Brasileiros, segundo o IBGE, em 2013 a estimativa de animais de companhia no Brasil era de aproximadamente 132,4 milhões. Já em 2018, mediante a uma atualização promovida pelo Instituto Pet Brasil, os números aumentaram para 139,3 milhões, sendo 54,2 milhões de cães; 39,8 milhões de aves; 23,9 milhões de gatos; 19,1 milhões de peixes e 2,3 milhões de répteis e pequenos mamíferos (Geraldes, 2019).

Em relação as regiões do Brasil, a que se destaca com a maior concentração de animais de estimação é a região Sudeste com 47,4\%; seguido pela Nordeste com 21,4\%; Sul com 17,6\%; Centro-Oeste com 7,2\% e Norte com 6,3\% (Geraldes, 2019).

Com essa crescente relação do animal com o ser humano, é importante realizar levantamento populacional nas cidades, pois com esses dados é possível realizar campanhas educacionais. Diante do contexto, o trabalho teve como objetivo avaliar ocorrência de caninos e felinos domiciliados no município de Pelotas, buscando relacionar os fatores que levaram a escolha de ter um pet em casa. Para posteriormente elaborar uma campanha de conscientização sobre reprodução em cães e gatos.

\section{Metodologia}

O presente trabalho faz parte do projeto de pesquisa, ensino e extensão em reprodução da faculdade de veterinária da Universidade Federal de Pelotas. O grupo atua junto com a comunidade em geral da cidade de Pelotas - RS, alguns projetos de extensão. O qual, atua com a conscientização da população em geral sobre os tumores prostáticos em cães e gatos. Como parte do projeto, buscou-se identificar a ocorrência de cães e ou gatos no município de Pelotas, para que a partir desses dados fosse elaboradas campanhas de conscientização junto à comunidade. 
Para isso, elaborou-se uma pesquisa quali-quantitativo, que segundo LÜDKE, MENGA (2018) a pesquisa qualitativa busca compreender o fenômeno estudado, no nosso caso a ocorrência de cães e gatos no município de Pelotas. Para isso, optouse a utilização da plataforma do Google Forms para que fosse possível abranger o maior número de pessoas e ainda a diversidade, também a praticidade que formulários de pesquisas on-line proporcionam. O questionário foi dividido em três partes, sendo a primeira com questões voltadas para os tutores, a segunda foi voltada para identificar se possui pet e qual o tipo de pet e quantos eles têm, e a terceira parte é identificar qual o motivo que levaram a ter um pet em casa. O questionário foi disponibilizado de forma on-line na plataforma eletrônica, durante uma semana no do mês de setembro de 2019, através do link https://docs.google.com/forms/d/1sz8dLs1-FD7HLzDKNRVzpJZv1FSMHVG5LQ0u0vxefAE/viewform?fbclid=IwAR2cvj 9jQBJFWK_sZQCEqn03ovpUSZHLou3WRi4uasCUxTrHwGLI1E08YPY\&edit_requested=true. Sendo compartilhado o link em mídias sociais relacionadas ao município de Pelotas - RS. Os dados foram analisados pelo programa SPSS Statistics 25, através da análise descritiva e ainda o teste q-quadrado, adotando $\mathrm{P}<0,05$ para significância e $\mathrm{P}<0,10$ como tendência.

\section{Resultados e Discussões}

Foi obtido um total de 300 respostas, no entanto como o objetivo foi analisar os residentes do município de Pelotas RS, descartou-se 27 respostas de outros municípios. A faixa etária dos participantes foram a maioria 21 a 30 anos com 114(41,8\%), 31 a 49 anos foi de 69(25,3\%), 59(21,6\%) das pessoas tinham idade acima dos 40 anos e apenas 31(11,4\%) eram dos 15 aos 20 anos. Em relação ao gênero, 209 (76,6\%) eram do gênero feminino e 64 (23,4\%) eram do gênero masculino. O tipo de moradia, mostrou que $170(62,3 \%)$ residem em casas e 103 (37,7\%) residem em apartamentos, mostrando que a maioria reside em casas. Ainda relacionado a moradia, $147(53,8 \%)$ consideram o espaço onde residem como médio, $65(23,8 \%)$ consideram pequeno e $61(22,3 \%)$ consideram grande.

A presença de animais de estimação em casa, está presente nos lares de $236(86,4 \%)$ das pessoas que responderam. Resultados esses, vão ao encontro ao encontro com os dados de 2012 que segundo Domingues (2012), sessenta e cinco por cento dos domicílios do país possuem um animal de estimação, representados por 32 milhões de cachorros e aproximadamente 16 milhões de gatos, em sua grande maioria. Além disso, nos mostra que os animais de estimação estão entrando dentro da família como um membro, na busca de companhia ou afetividade ou até mesmo a questão de status perante a sociedade (Rocha 2015).

Apenas 37(13,6\%) não possuem animais. Desses, 23(13,6\%) foi perguntado qual o motivo que levou eles a não possuírem animais em casa, onde obtivemos animais falta de tempo para se dedicar ao animal 19(7,0\%), sendo seguido por $12(4,4 \%)$ apontam que a falta de espaço e apenas $2(0,7 \%)$ por não gostarem de animais. Por outro lado, uma possível explicação para o crescimento do número de pets e busca afetiva por um animal de estimação, seria em consequência das modificações que a sociedade vem enfrentando, no sentido de encolhimento das famílias pela redução da natalidade e novos estilos de vida (Moutinho; et al.; 2015). Esses dados são um reflexo do crescente aumento de pets no Brasil.

Dos que afirmaram ter animais de estimação em casa, questionou-se quais eram os pets que eles possuíam (Tabela 1), sendo que a presença do cão sobressaiu aos demais animais com 107(39,2\%) das respostas. No entanto, podemos observar que a presença de gatos nos lares da cidade de Pelotas - RS chega a 28\% quando analisamos as respostas das pessoas possui um gato pelo menos, mostrando a tendência do aumento do número de gatos em relação ao número de cães. Nesse aspecto, a pesquisa do Instituto Pet Brasil aponta que, entre 2013 e 2018, o número de felinos nos lares brasileiros cresceu 8,1\%; já o de cães aumentou $3,8 \%$, menos da metade (Zuba, 2019).

Indo nesse sentido da questão da moradia versus qual o tipo de moradia, existe uma relação positiva $(\mathrm{p}=0,000)$ quando analisados a moradia apartamento versus cão, gato. Onde observamos que os felinos estão mais presentes em apartamentos do que em casa, tendo 32 (31,1\%) de gatos. Quando analisamos a moradia casa, os cães predominam com 76 (44,7\%), isso mostra que as pessoas que moram em apartamentos procuram um animal de estimação que seja mais simples os cuidados, ou também 
como a cidade de Pelotas - RS tem uma parte da população formada por estudantes. Esses pontos levam aos tutores possuírem gatos em casa é que eles exigem cuidados mais simples e espaços menores quando comparados aos cães, mais ainda quando o número de pessoas mora sozinhas, tendo essa tendencia a ocorrer em cidades maiores (Geraldes, 2019). Sendo essa realidade observada na nossa pesquisa, já que Pelotas - RS é a terceira maior cidade do estado do Rio Grande do Sul e com uma boa parte da população formada por estudantes (UFPel, 2019).

Também se perguntou qual o motivo que levou a ter o pet em casa, 137(50,2\%) o amor aos animais e $103(37,8 \%)$ o companheirismo. Quando relacionamos o companheirismo proporcionado pelos pets, podemos relacionar que eles podem estar preenchendo lacunas emocionais na família, como as deixadas pela saída dos filhos de casa na chamada "síndrome do ninho vazio", assumindo este papel como substituto (Diniz 2005). Outro ponto, é que a presença de animais de estimação, proporciona sensação de relaxamento, felicidade, amor, companheirismo, diminuindo o sentimento de solidão e angustia (Tatyanne; Tommy, 2016). Segundo estudos, esta interação tende a produzir uma redução nos níveis de ansiedade, diminuindo o aparecimento ou a progressão de patologias correlacionadas ao estresse (Domingues et al., 2015). Além disso, outros benefícios proporcionados pelos animais aos seres humanos: a companhia, a promoção de mudanças positivas no autoconceito e no comportamento das pessoas (Faraco 2008).

Tabela 1. Qual o tipo de Pet que possui em casa?

\begin{tabular}{|c|c|c|}
\hline & Qual seu Pet? & $\mathrm{n}(\%)$ \\
\hline Cão & & $107(39,2)$ \\
\hline Cão e gato & & $63(23,1)$ \\
\hline Cão, gatos e outros & & $8(2,9)$ \\
\hline Cão e outros & & $9(3,3)$ \\
\hline Gato & & $42(15,4)$ \\
\hline Outros & & $8(3,0)$ \\
\hline
\end{tabular}

Fonte: Autores.

Ainda foi constatado que esses pets são em sua grande maioria sem raça definida (SRD) (146 - 53,5\%), com raça definida (56 -20,5\%) e quando o tutor possuía mais de um animal, pelo menos um deles é SRD e outro com raça definida (3914,3\%). O número de cães presentes nos domicílios, foi observado que 147 (53,9\%) possui até dois cães, 41(15\%) possuem entre três e cinco cães, 10 (3,7\%) possuem mais que cinco cães, 75(27,5\%) não possuem cães. Já o número de gatos, 87(31,8\%) possuem até dois gatos, $26(9,5 \%)$ e $160(58,6 \%)$ não possuem gatos. Esses dados mostram que a presença de cães é maior que a de gatos. Desses tutores, foi perguntado se eles tinham adotado ou comprado seu animal de estimação; sendo que 176(64,5\%) adotaram seu pet, mostrando que na cidade de Pelotas os tutores buscam a adoção como meio de se ter um animal de estimação. Pois a adoção de animais, ajuda a diminuir o número de animais em abrigos e ao mesmo tempo proporciona a família uma experiência da adoção (Hawes et al.; 2020),

Analisando o tipo de moradia, observamos que 170 (62,3\%) moram em casa e 103(37,7\%) moram em apartamento. E quando indagados como eles consideram o espaço onde mora, $147(53,8 \%)$ pessoas consideram como médio o espaço, 65 (23,8\%) consideram pequeno e 61(22,3\%) consideram grande. Esses dados podem influenciar no tipo de pet que tem em casa e também o número deles.

Já a relação gênero versus se tem animais de estimação em casa, observamos a existência dessa relação ( $\mathrm{p}=0,034)$, onde o gênero influencia em ter pets em casa, sendo observado que 186 (89\%) das pessoas do gênero feminino possui animais de estimação. Já a relação da moradia com a presença de pets, 78 (75,7\%) que residem em apartamentos possuem pets em casa, e 
158(92,9\%). Essa é uma tendência que ocorre, onde as mulheres são as que mais possuem um pet, e além disso são as que mais consomem produtos relacionados ao mercado pet, como ração, roupinha, etc... (Fonseca et al.; 2017).

A relação moradia versus o número de cães mostrou-se positiva ( $\mathrm{p}=0,0001)$, onde quem mora em apartamento possui no máximo dois cães $47(45,6 \%)$, e já quem reside em casas 100(58,8\%) possuem até dois cães, 38(22,4\%). Observando essa mesma relação, só que com gatos, 36(35\%) possuem até dois gatos em apartamentos, e 51(30\%) que residem em casa, possuem até dois gatos, e 22(12,9\%) possuem de três a cinco gatos.

A realização desse tipo de trabalho, é indispensável para auxiliar em futuros trabalhos educativos que busquem a conscientização de tutores de pets. Pois a convivência com animais agrega diversos benefícios psicológicos, fisiológicos e sociais aos seres humanos, mas pode causar, quando a criação de animais é inadequada, alteração dos padrões de bem-estar dos animais, possibilidade de transmissão de doenças, ocorrências de agressões e contaminação ambiental (Lima \& Luna, 2012). Com base nesses resultados obtidos nessa pesquisa, será possível a realização de campanha educacional sobre o Novembro Azul Canino e com isso aproximar os graduandos com os tutores dos pets. Pois as ações de extensão possibilitam que a comunidade acadêmica leve conhecimentos ao público externo e forme agentes multiplicadores (Ishikura et al., 2017). Além disso, os graduandos têm a oportunidade de iniciar um contato com a população local e conviver diretamente com tutores de animais de estimação (Budziak et al., 2017; Carvalho et al., 2017).

\section{Conclusão}

Concluímos que as pessoas que residem em Pelotas - RS se identificam com o gênero feminino são os que mais possuem pets em casa, e que os tutores que moram em apartamentos dão preferência por gatos, por residirem em sua grande maioria sozinhos. A adoção dos pets foi dada com a preferência pelos tutores, como forma de ter um pet em casa. Além disso, há a tendência de que os pets estão ocupando um lugar dentro da família, já que muitos moram sozinho e ele torna-se um amigo e até mesmo um filho.

Estudos como esses são importantes, quando se planeja desenvolver campanhas de conscientização da população, pois é possível identificar as questões de faixa etária dos tutores, qual é a preferência, entre outras questões. Além disso, se faz necessário um estudo que abrangesse toda a região Sul do estado do Rio Grande do Sul, para ter um perfil dos tutores de pet da região.

\section{Agradecimentos}

O presente trabalho foi realizado com apoio da Coordenação de Aperfeiçoamento de Pessoal de Nível Superior Brasil (CAPES) - Código de Financiamento 001” do segundo autor.

\section{Referências}

Budziak, C., Pimpão, C. T., Montoya, I. K., Júnior, J. A. V., \& Moraes, P. F. (2017). A importância do projeto Campanha de Castração na formação do profissional médico veterinário. Revista Acadêmica: Ciência Animal, 8(3), 361-370. https://doi.org/10.7213/cienciaanimal.v8i3.10946

Carvalho, S. M. R., Sousa, W. L., Rodrigues, A. A., Sá, M. V., Sá, I. S., Batista, R. M. O., Rocha, D. S., Santos, J. S., Galeno, L. S., \& Júnior, A. A. N. M. (2017). Atendimento clínico veterinário em cães e gatos na comunidade Serra Nova do município de Bom Jesus-PI. PUBVET, 12(2), 1-4. https://doi.org/10.22256/pubvet.v12n2a40.1-4

Diniz, E. (2005). O bem estar dos animais. Pet shop Brasil Business, 9(88).

Domingues, L. R. et al. (2015). Guarda responsável de animais de estimação na área urbana do município de Pelotas, RS, Brasil. Ciencia e Saúde Coletiva, 20(1), 185-192.

Domingues, L. R. (2012). Posse Responsável de Cães e Gatos na Área Urbana do Município de Pelotas, RS, Brasil. 2012.87 p. Dissertação (Mestrado em Epidemiologia). Universidade Federal de Pelotas, Pelotas, 2012. http://repositorio.ufpel.edu.br/bitstream/123456789/1
. 955/1/Dissertacao_Lidice_Domingues.pdf. 
Faraco, C. B. (2008). Interação Humano-Animal. Ciência veterinária nos trópicos. 1.

Ferreira, M. S. S., Aleixo, G. A. S., Melo, F. V. S., Xavier, A. N., et al. (2015). Incentivo à posse responsável e controle populacional de cães e gatos com ações educativas aplicadas a crianças de Garanhuns/PE. Revista de Educação Continuada Em Medicina Veterinária e Zootecnia do CRMV-SP, 13(3), 80.

Fonseca, G. O., Hespanhol, R. M., \& Pereira, D. R. (2017). Análise mercadológica do segmento pet: estudo de caso utilizando aprendizado de máquina. Revista Latino-Americana de Inovação e Engenharia de Produção, 5(8). 117-135.

Geraldes, D. (2019). Censo Pet: 139,3 milhões de animais de estimação no Brasil - Editora Stilo. https://www.editorastilo.com.br/censo-pet-1393-milhoes-deanimais-de-estimacao-no-brasil/

Giumelli, R. D., \& Santos, M. C. P. Convivência com animais de estimação: um estudo Fenomenológico. (2016). Rev. abordagem gestalt. 22(1).

Haes, S.M., Kerrigan, J. M., Hupe, T., \& Morris, K. N. (2020). Factors Informing the Return of Adopted Dogs and Cats to an Animal Shelter Animals. Basel. 10(9), 1573-1780.

Ishikura, J. I., Cordeiro, C. T., Silva, E. C., Bueno, G. P., et al. (2017). Minihospital veterinário: guarda responsável, bem estar animal, zoonoses e proteção à fauna exótica. Revista Brasileira de Extensão Universitária, 8(1), 23-30. https://doi.org/10.24317/2358-0399.2017v8i1.3123

Lampert, M. (2014). Benefício da Relação Homem-animal. Trabajo de finalización del curso de veterinaria (TCC). Pontificia Universidad Catolica del Peru, $8(33), 44$.

Lima, A. F. M., \& Luna, S. P. L. (2012). Algumas causas e consequências da superpopulação canina e felina: acaso ou descaso? Revista de Educação Continuada Em Medicina Veterinária e Zootecnia, 10(1), 32-38. https://doi.org/10.36440/recmvz.v10i1.258

Ludke, M. \& Andre, M. E. D. A. (2013). Pesquisas em educação: uma abordagem qualitativa. LTC - Livros Técnicos e Científicos Editora Ltda

Magnabosco, C. (2006). População domiciliada de cães e gatos em São Paulo: perfil obtido através de um inquérito domiciliar multicêntroco. Dissertação, Departamento de Epidemiologia da Faculdade de Saúde Pública da Universidade de São Paulo. 98p. https://teses.usp.br/teses/disponiveis/6/6132/tde-06032007104453/publico/Dissertacao_CMagnabosco.pdf

Martins, E. (2019). Cálculo amostral para pesquisa quantitativa: Aprenda como fazer. https://blog.mettzer.com/calculo-amostral-pesquisa-quantitativa

Montague, M.J., LI, G., Gandolf, B.et al. (2014). Comparative analysis of the domestic cat genome reveals genetic signatures underlying feline biology and domestication. Proc Natl Acad Sci USA. 2, 111(48): 17230-17235. 10.1073/pnas.1410083111

Moutinho, F. F. B., Nascimento, E. R., \& Paixão, R. L. (2015). Percepção da sociedade sobre a qualidade de vida e o controle populacional de cães não domiciliados. Ciência Animal Brasileira, 16(4), 574-588.

Paloma, O. (2019). Estudos apontam que a domesticação de gatos começou há cerca de 10 mil anos - Ciência e Saúde. Correio Braziliense. https://www.correiobraziliense.com.br/app/noticia/ciencia-e-saude/2011/12/25/interna_ciencia_saude,284025/estudos-apontam-que-a-domesticacao-de-gatoscomecou-ha-cerca-de-10-mil-anos.html

Rocha, R F. C. (2015). Critérios de Decisão de Compra de Ração para Cães: um estudo exploratório. Dissertação (Mestrado em Marketing). Universidade de Lisboa, Instituto Superior de Economia e Gestão, 2015. http://www.repository.utl.pt/bitstream/10400.5/10844/1/DM-RFCR-2015.pdf

Rodrigues, L. et al. (2012). Posse Responsável De Cães E Gatos Na Área Urbana Do Município De Pelotas, RS, Brasil. Dissertação (Programa de Pós-graduação em Epidemiologia), 87, 2012.

Silvano, D., Bendas, A. J. R., Miranda, M. G. N., Pinhão, R., et al. (2010). Sensibilização de crianças. Divulgação dos princípios da guarda responsável: uma vertente possível no trabalho de pesquisa a campo. Revista Eletrônica Novo Enfoque, 9(9), 64-86.

UFPel. Universidade Federal de Pelotas - International Association of People-Environment Studie. 2019. International Association of People-Environment Studie

Zuba, F. Gatos podem superar cães como animais de estimação no Brasil em cinco anos, diz veterinária de BH. G1 - Minas Gerais, Setembro, 2019. https://g1.globo.com/mg/minas-gerais/noticia/2019/09/08/gatos-podem-superar-caes-como-animais-de-estimacao-no-brasil-em-cinco-anos-diz-veterinaria-debh.ghtml 